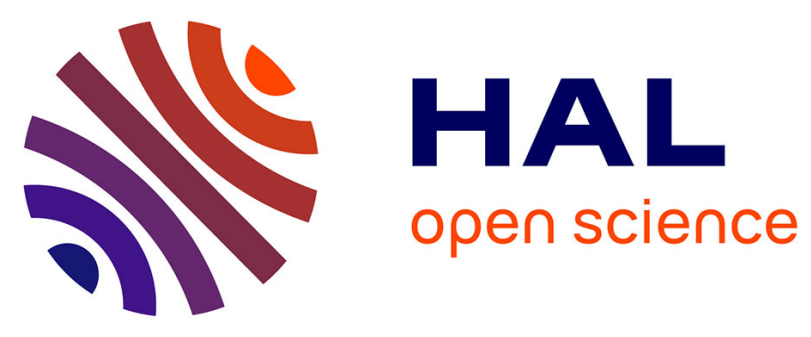

\title{
Double-Heterojunction Bipolar Transistor as THz Detector for Communications
}

\author{
Isidore Diouf, Philippe Nouvel, Luca Varani, Annick Pénarier, Nina \\ Diakonova, Dominique Coquillat, V. Nodjiadjim, M. Riet, Nicolas Zerounian, \\ F. Aniel, et al.
}

\section{To cite this version:}

Isidore Diouf, Philippe Nouvel, Luca Varani, Annick Pénarier, Nina Diakonova, et al.. DoubleHeterojunction Bipolar Transistor as THz Detector for Communications. 2021 46th International Conference on Infrared, Millimeter and Terahertz Waves (IRMMW-THz), Aug 2021, Chengdu, China. 10.1109/IRMMW-THz50926.2021.9566983 . hal-03413094

\section{HAL Id: hal-03413094 https://hal.science/hal-03413094}

Submitted on 23 Nov 2021

HAL is a multi-disciplinary open access archive for the deposit and dissemination of scientific research documents, whether they are published or not. The documents may come from teaching and research institutions in France or abroad, or from public or private research centers.
L'archive ouverte pluridisciplinaire HAL, est destinée au dépôt et à la diffusion de documents scientifiques de niveau recherche, publiés ou non, émanant des établissements d'enseignement et de recherche français ou étrangers, des laboratoires publics ou privés. 


\title{
Double-Heterojunction Bipolar Transistor as THz Detector for Communications
}

\author{
I. Diouf ${ }^{1}$, P. Nouvel ${ }^{1}$, L. Varani ${ }^{1}$, A. Pénarier ${ }^{1}$, N. Diakonova ${ }^{2}$, D. Coquillat ${ }^{2}$, V. Nodjiadjim ${ }^{3}$, M. Riet ${ }^{3}$, \\ N. Zerounian ${ }^{4}$, F. Aniel ${ }^{4}$, and S. Blin ${ }^{3}$ \\ ${ }^{1}$ IES, Univ Montpellier, UMR CNRS 5214, Montpellier FR \\ ${ }^{2}$ L2C, Univ Montpellier, CNRS, Montpellier FR \\ ${ }^{3}$ III-V Lab, 91767 Palaiseau, FR \\ ${ }^{4}$ Université Paris-Saclay, CNRS, Centre de Nanosciences et de Nanotechnologies, 91120, Palaiseau FR
}

\begin{abstract}
We investigate the use of an InP-based doubleheterojunction bipolar transistor as a detector for wireless communications around $300 \sim \mathrm{GHz}$. The sensitivity of the detector, along with its complex output impedance are characterized for a transistor (un)coupled to a log-spiral antenna, at different biases. A real-time uncompressed high-definition video signal is successfully transmitted at $1.5 \mathrm{Gbps}$ in a heterodyne configuration.
\end{abstract}

\section{INTRODUCTION}

$\mathrm{N}$ EXT-GENERATION wireless communications systems require carrier frequencies in the $\mathrm{THz}$ domain. Among the possible high-speed detectors, transistors are attractive due to their inherent compatibility with monolithic microwave integrated circuits. $\mathrm{THz}$ detection have been reported using either field-effect transistor [1] or double-heterojunction bipolar transistors (DHBT) [2], but only the former was evaluated for high-data-rates communications either in a standard amplitude-modulation scheme [3] or heterodyne scheme [4]. In this paper, we report for the first time the full experimental study of InP-based double-heterojunction bipolar transistors for terahertz wireless communications, with specific focuses on sensitivity, modulation bandwidth and complex output impedance.

\section{DBH TRANSISTOR AS THz DETECTOR}

The transistor under study is a $0.7 \times 5 \mu \mathrm{m}$ emitter-size $\mathrm{InP}$ DHBTs dedicated to $100 \mathrm{Gpbs}$ applications [5]. The device structure includes a 40-nm InP emitter, a 28-nm compositionally graded In-Ga- As base, which is highly Cdoped and 130-nm composite collector containing a In-Ga-As spacer and an InP delta-doped layer. The static current gain was around 20 and the common-emitter breakdown voltage was above $5 \mathrm{~V}$. These devices demonstrate transition frequency and maximum frequency of oscillation above 320 and $280 \mathrm{GHz}$ respectively, but to optimize the $\mathrm{THz}$ detected signal, these transistors are biased in an unconventional way that dramatically reduces these frequencies: best detection is obtained if the transistor is biased between base and emitter, the latter being grounded and the collector being opened. In this configuration, the DHBT is a non-linear component offering envelope detection between collector and emitter.

Quasi-static and dynamic characterization of the transistor are conducted using the experimental setup shown in Fig. 1. The THz source is a frequency-multiplied (x24) chain driven by a synthesizer. The last stage of the chain is a second-harmonic mixer allowing a carrier-suppressed amplitude modulation at frequency $f_{m}$. For THz characterizations, one synthesizer is used to control the carrier frequency, while the second one is used to

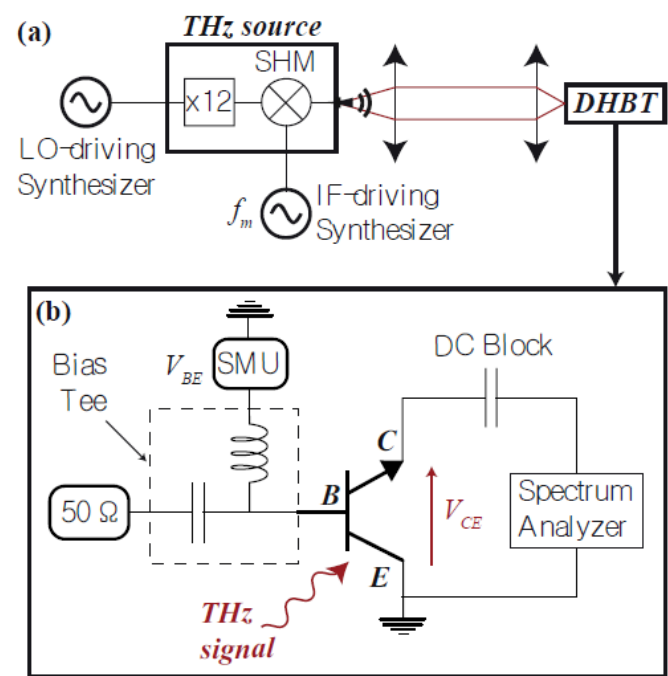

Fig. 1. THz characterization setup of the DHBT (a) and details of the transistor biasing scheme (b).

apply a sinusoidal modulation. The THz beam is then extracted thanks to a diagonal horn antenna, collimated by a $10-\mathrm{cm}$ focallength Teflon lens, then focused on the transistor using a similar lens. Due to the non-linear response of the transistor excited by a carrier-suppressed amplitude-modulated signal, a beat signal at $2 f_{m}$ is measured between collector and emitter using a spectrum analyzer. The amplitude of this beat note is used to evaluate the sensitivity of the transistor, either as a function of the bias voltage, of the carrier or modulation frequencies.

As shown in Fig. 2(a), the sensitivity, defined here as the ratio of the collector-emitter rms voltage to the input $\mathrm{THz}$ power increases with the biasing voltage up to $0.75 \mathrm{~V}$. One should note that this sensitivity is not corrected by any effective surface area of the transistor, since the aim of this study is not to evaluate the intrinsic sensitivity of the transistor but rather its true output signal required to realize an operating communication system. These sensitivity measurements can be correlated to complex impedance measurements conducted using a vectorial network analyzer. As shown in Fig. 2(a), as the base-emitter bias increases, the real part of the impedance does not significantly change while the imaginary part reduces drastically, thus allowing for a better matching with the 50 -ohms spectrum analyzer used for these measurements, but also with typical 50ohms amplifiers required in a communication system. Optimum detection and optimum impedance matching are thus obtained for a biasing of $0.74 \mathrm{~V}$. 

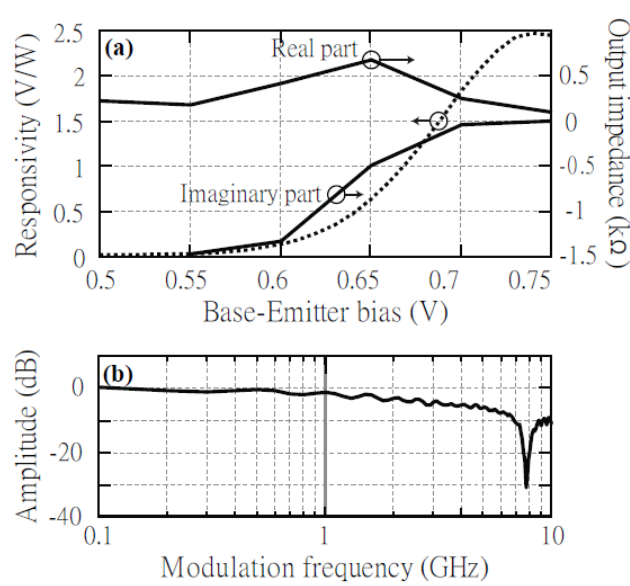

Fig. 2. Main characterization of the DHBT. Figure (a) presents the sensitivity of the transistor (dashed-line) as a function of the bias voltage for a $0.7-\mathrm{mm}$ input beam waist. The full lines show the complex output impedance of the transistor measured at $300 \mathrm{MHz}$ (real and imaginary parts). Figure (b) shows the modulation bandwidth of the transistor biased at $0.75 \mathrm{~V}$. For this measurement, a sinusoidal carrier-suppressed amplitude-modulation is applied to a $300-\mathrm{GHz}$ signal and the amplitude of the demodulated signal at the transistor output is measured as a function of the sinusoidal frequency.

The transistor bandwidth is evaluated by measuring the output signal (collector-emitter voltage) as a function of modulation frequency. We show in Fig. 2(b) that the typical cut-off frequency of the transistor is about $2 \mathrm{GHz}$. As previously mentioned, if compared to the intrinsic transition frequency, such a degradation is explained by the unconventional biasing scheme of the transistor, which is unfortunately required to maintain $\mathrm{THz}$ detection. Different biasing schemes could be investigated to determine if the modulation frequency can be increased without significant degradation of the sensitivity, however present modulation bandwidth should allow the transmission of high-definition videos, a highly-demanded $\mathrm{THz}$ application.

\section{THz COMMUNICATION}

$\mathrm{THz}$ communications are challenging using transistors as $\mathrm{THz}$ detectors due to their limited sensitivity. The possible datarates has been evaluated as a function of sensitivity in Ref. [4] for different detected $\mathrm{THz}$ powers, and shows that a 1.5-Gbps high-definition video should be successfully transmitted for a detected power of $60 \mu \mathrm{W}$ that exceeds the available power of the source presented in Fig. $1(10 \mu \mathrm{W})$. Additionally, effective communication is prohibited using an envelope detector excited by a carrier-suppressed amplitude-modulated signal. Therefore, a heterodyne scheme was implemented, similarly to the one reported in [4], to increase the effective detected power thanks to a high-power continuous-wave source, and to make possible the communication. To demonstrate this communication, a HDMI signal was converted to a serial-data-interface signal to drive the last-stage mixer of the multiplication chain that delivers the $\mathrm{THz}$ signal. The transistor output was amplified using two 20-dB 1-GHz amplifiers, and the amplified signal was converted to a HDMI port connected to the input of a TV. A stable real-time transmission of this high-definition video at
1.5 Gbps using a $300-\mathrm{GHz}$ carrier frequency was confirmed, thus proving the potential of these transistors for such $\mathrm{THz}$ applications.

\section{SUMMARY}

We have shown that double-heterojunction bipolar transistors can be used for $\mathrm{THz}$ communications for moderate data rates of few Gbps. One major limitation is the strong imaginary part of the collector-emitter output impedance in the biasing configuration that maximizes the sensitivity to $\mathrm{THz}$ waves. Traditional biasing schemes offer extremely high bandwidth but to the price of a very low sensitivity thus preventing any successful communication. As an alternative, antenna-coupled DHBT were processed with a 50x sensitivity improvement that opens the path to higher-data rates demonstrations.

\section{AKNOWLEDGEMENTS}

This work was financially supported by the ANR project NADIA Integrated NAnoDetectors for terahertz Applications (ANR-13-NANO-0008) and "Hermes platform" for providing the equipements needed to accomplish this work.

\section{REFERENCES}

[1]. W. Knap et al., "Field effect transistors for terahertz detection: Physics and first imaging applications," J. Infrared Millimeter Terahertz Waves, vol. 30, pp. $1319-1337,2009$

[2]. V. Vassilev, H. Zirath, R. Kozhuharov and S. Lai, "140-220-GHz DHBT detectors," IEEE Trans. on Microwave Theory and Tech., vol. 6, no. 6, pp. 2353-2360. 2013

[3]. S. Blin et al., "Wireless communication at $310 \mathrm{GHz}$ using GaAs high[3]. S. Blin et al., "Wireless communication at $310 \mathrm{GHz}$ using GaAs high-
electron-mobility transistors for detection," J. of Comm. and Networks, pp. $559-568,2013$

[4]. S. Blin et al., "Terahertz heterodyne communication using GaAs fieldeffect transistor receiver," IEEE Electron Device Letter's, vol. 38, no. 1, pp. 20 23, 2017

[5]. J.-Y. Dupuy et al., "A large-swing $112-\mathrm{Gb} / \mathrm{s}$ selector-driver based on a differential distributed amplifier in InP DHBT," IEEE Trans. on Microwave Theory and Tech., vol. 61, no. 1, pp. 517-524. 2013 